\title{
Synchronous early-stage breast cancer and axillary follicular lymphoma diagnosed by core needle biopsy: A case report
}

\author{
RYOTARO ETO $^{1}$, RIKIYA NAKAMURA ${ }^{1}$, NAOHITO YAMAMOTO ${ }^{1}$, TOSHIKO MIYAKI $^{1}$, SHOKO HAYAMA $^{1}$, \\ ITARU SONODA $^{1}$, MAKIKO ITAMI $^{2}$, HIDEKI TSUJIMURA ${ }^{3}$, HIDEYUKI HASHIMOTO ${ }^{4}$ and MASAYUKI OTSUKA ${ }^{5}$ \\ ${ }^{1}$ Division of Breast Surgery; ${ }^{2}$ Division of Diagnostic Pathology; ${ }^{3}$ Division of Hematology-Oncology, Chiba Cancer Center, \\ Chiba 260-8717; ${ }^{4}$ Chiba Foundation for Health Promotion and Disease Prevention, Chiba 261-0002; \\ ${ }^{5}$ Department of General Surgery, Chiba University Graduate School of Medicine, Chiba 260-8677, Japan
}

Received February 18, 2021; Accepted July 28, 2021

DOI: $10.3892 / \operatorname{mco} .2021 .2436$

\begin{abstract}
Synchronous double cancers are an infrequent finding. The focus of this study was a case of diagnosed synchronous double breast cancer (BC) and axillary (Ax) follicular lymphoma (FL). The patient was a 73-year-old woman who had been visiting her local doctor for follow-up of a fibroadenoma of the left breast, and was referred to our hospital after being diagnosed with invasive ductal carcinoma (IDC) of the left breast. Ultrasonography (US) revealed enlarged Ax lymph nodes (LNs) and US-guided core needle biopsy (CNB) was performed. CNB revealed no metastasis of IDC; however, a diagnosis of FL was made. Therefore, the patient was diagnosed with synchronous double $\mathrm{BC}$ and $\mathrm{Ax}$ FL and underwent partial surgical resection of the $\mathrm{BC}$ and close monitoring of the FL. To the best of our knowledge, this is the first case of malignant lymphoma diagnosed by $\mathrm{CNB}$ of Ax LNs during preoperative BC screening. CNB allows for a shorter waiting time for the examination, and it is considered to be minimally invasive, cost-effective and non-inferior to surgical resection in terms of specimen volume. Therefore, active preoperative evaluation of Ax LNs using US-guided CNB may contribute to BC staging, and may also help diagnose synchronous cancers.
\end{abstract}

Correspondence to: Dr Ryotaro Eto, Division of Breast Surgery, Chiba Cancer Center, 666-2 Nitonacho, Chuo, Chiba 260-8717, Japan

E-mail: etounoago2424@gmail.com

Abbreviations: CNB, core needle biopsy; FA, fibroadenoma; IDC, invasive ductal carcinoma; FL, follicular lymphoma; BC, breast cancer; ML, malignant lymphoma; SLNB, sentinel lymph node biopsy; PET-CT, positron emission tomography-computed tomography; FNAC, fine-needle aspiration cytology

Key words: breast cancer, invasive ductal carcinoma, follicular lymphoma, core needle biopsy, synchronous double cancer

\section{Introduction}

Synchronous double breast cancer (BC) and axillary (Ax) follicular lymphoma (FL) have different treatment priorities, depending on their respective stage. BC may be treated with surgical resection, chemotherapy, radiation therapy and endocrine therapy, or a combination of these modalities, according to cancer type and stage. However, FL is mainly managed using chemotherapy or careful observation, based on the tumour volume. The majority of the cases of synchronous BC and malignant lymphoma (ML) of the Ax lymph nodes (LNs) are commonly diagnosed using sentinel LN biopsy (SLNB) or Ax LN dissection at the time of surgery for BC (1-11). To the best of our knowledge, the case presented herein was the first case in which synchronous Ax FL was diagnosed using core needle biopsy (CNB) of the Ax LNs during staging examination for $\mathrm{BC}$. In the present case, the two synchronous cancers were staged to establish the treatment priority. We herein report the case details, along with a review of the related literature.

\section{Case report}

The patient was a 73-year-old woman who was followed up by a local doctor for a fibroadenoma of the left breast diagnosed by ultrasound (US) examination 4 years prior. The patient had no subjective symptoms or specific disease-related history and had undergone spontaneous menopause at 50 years of age. The family history included a diagnosis of $\mathrm{BC}$ in the patient's maternal aunt. The patient had been subjected to US examination in June 2020, and a tumor was detected in the left breast. CNB of the tumor was performed, and the patient was diagnosed with invasive ductal carcinoma (IDC) of the left breast and was referred to Chiba Cancer Center in September 2020.

US examination of the left breast and Ax LNs revealed a large 8-mm hypoechoic lesion with irregular margins in the nipple areola-complex of the left breast, situated in the middle and immediately above the nipple. The histological diagnosis was IDC, histological grade I (tubule formation score 2, nuclear atypia score 2 , and mitotic count score 1), estrogen receptor-positive (90\%), progesterone receptor-negative $(0 \%)$ 
and HER2 score 0 (Fig. 1). Enlarged left Ax LNs and loss of the medulla were detected (Fig. 2). Ax LN metastasis of IDC was suspected; therefore, US-guided CNB was performed using a 16G 22-mm needle, and four specimens were collected. Histopathological examination of the Ax LN samples revealed the formation of lymphoid follicles consisting mainly of medium-sized centrocytes with occasional large centroblasts. Immunostaining revealed that most of the follicular component cells were positive for CD10, CD20, Bcl-2 and Bcl-6, and negative for CD3, multiple myeloma oncogene 1 (MUM1) and Epstein-Barr virus-encoded small RNA (EBER). The CD21-positive dendritic cells almost coincided with the follicles, leading to the diagnosis of FL (Fig. 3). The tissues were fixed using $10 \%$ neutral buffered formalin at $25^{\circ} \mathrm{C}$ for $24 \mathrm{~h}$. After fixation, the specimen was cut into 5-7-mm sections, which were then dehydrated using ethanol, impregnated and embedded in paraffin in a closed automatic fixation unit during a 22-h program. The paraffin-embedded specimen was then cut into 4- $\mu \mathrm{m}$ sections using a sliding microtome. The sections were then placed on glass slides, spread using a spreader, and dried in an oven at $60^{\circ} \mathrm{C}$ for $20 \mathrm{~min}$. The following equipment was used for immunostaining: CD20, CD3, Bcl-2, Bcl-6 and EBER: VENTANA BenchMark ULTRA (Roche Diagnostics K.K.; cat. no. 13B1X00201000050); and CD10, MUM1 and CD21: Dako Omnis (Agilent Technologies Japan, Ltd; cat. no. 13B3X10204000004). Nikon Eclipse Ni-U Biological Microscope (Nikon Corporation) was used for imaging at a magnification of $\mathrm{x} 20$.

Blood examinations revealed that the IL-2 receptor level was $1,859 \mathrm{U} / \mathrm{ml}$ (normal range, 122-496 U/ml); however, there were no significant abnormalities in the blood cell count or liver enzyme levels, and the patient had no B symptoms (fever, weight loss or sweating).

The patient was referred to the Division of HematologyOncology at Chiba Cancer Center and underwent positron emission tomography computed tomography (PET-CT) examination, which revealed high ${ }^{18} \mathrm{~F}$-fluorodexyglucose accumulation in the mediastinal, bilateral axillary, abdominal para-aortic, iliac and bilateral inguinal LNs (Fig. 4). None of the LNs had enlarged beyond $3 \mathrm{~cm}$ in size, and none met the Groupe d' Etude des Lymphomes Folliculaires high tumour volume criteria; therefore, careful observation of the patient was decided based on the low tumour volume (12-14).

The patient was subjected to partial left mastectomy and SLNB [indigo carmine dye and ${ }^{99 \mathrm{~m}} \mathrm{Tc}$ gamma probe and intraoperative US-guided marking with patent blue dye and tattooing (15)] for the IDC. In addition, an enlarged LN (20 mm) was identified near the SLN, which was also resected. No BC metastasis was found in the resected SLN. Large and small follicular structures were observed in the enlarged LNs, which extended into the adipose tissue outside the LN capsule. Immunostaining revealed that the cells in the follicular area were positive for CD79a, CD20, CD10 and Bcl-2, and negative for CD3 and CD5, which was consistent with the diagnosis of FL. The pathologist reported no differences in the diagnosis or staging between the specimens obtained at surgery and those obtained by CNB preoperatively. The left BC was pT1aN0M0 stage I. The patient received oral adjuvant treatment with the aromatase inhibitor (AI) anastrozole ( $1 \mathrm{mg} /$ day for 5 years), as well as radiotherapy at a total dose of $50 \mathrm{~Gy}(2 \mathrm{~Gy} / \mathrm{fr} \times 25)$.
FL was continuously monitored by the Department of Hematology and Oncology. The disease status was stable disease at the 6-month postoperative follow-up.

\section{Discussion}

Synchronous BC and Ax ML is an infrequent occurrence with only a few cases reported to date. However, to the best of our knowledge, no case of ML diagnosed by US-guided CNB during preoperative screening for $\mathrm{BC}$ has been reported to date (1-11). In most cases of synchronous BC and Ax ML, a definitive diagnosis is obtained by SLNB or Ax LN dissection (1-10); this is because physical examination, incisional biopsy of Ax LNs, PET-CT and fine-needle aspiration cytology (FNAC) are the most commonly used methods for the assessment of Ax LNs during preoperative staging of BC $(16,17)$.

However, several clinical trials have reported the usefulness of FNAC for SLNB $(18,19)$. The advantages of CNB for patients and surgeons are as follows: i) It has a higher rate of diagnosis of BC metastasis compared with FNAC; ii) it allows for differentiation from other diseases; iii) it allows for an immunological histological diagnosis; and iv) it is as safe and simple to perform as FNAC.

First, Nakamura et al (20) reported the usefulness of CNB and concluded that it had a higher sensitivity for positive Ax LN metastases compared with FNA (CNB vs. FNA, 87.5-90 vs. 64.8-76.0\%, respectively) (21). Accurate diagnosis of metastases in the Ax LNs may help patients avoid unnecessary SNLB and reduce the operative time and cost.

When Ax LN metastasis of BC progresses, the lymphatic flow is altered due to the obstruction of the lymph vessels or nodes by the cancer cells, and the lymphatic flow increases to not only other Ax LNs, but also the parasternal LNs (22). Loss of the original lymphatic flow is considered to reduce the uptake of dye and isotope particles in the SLNs and decrease the identification and positive diagnosis rates of SLNB (23-25). Therefore, Ax LN dissection should be initially performed in cases with clinical evidence of Ax LN metastasis (N1-2), and the use of SLNB to accurately diagnose Ax LN metastasis should be limited to cases with no clinical evidence of Ax LN metastasis (N0) $(26,27)$. In the present case, the Ax LNs were significantly enlarged on imaging compared with normal LNs, and IDC metastasis was suspected. However, preoperative evaluation ruled out BC metastasis to the Ax LNs, and SLNB was performed. If the patient had been found to have metastasis to the Ax LNs (N1-2) on imaging and had not undergone CNB, Ax LN dissection would have been performed (28), which would be an over-invasive procedure for this patient. Considering that ML is not accompanied by abnormalities in the lymphatic pathway, but may affect the lymphatic drainage and other factors, it was determined as reasonable to perform SLNB by carefully tracking the lymphatic vessels.

Second, the assessment of the Ax LNs for BC may be inconsistent with the progression of primary BC. Fortunato et al (29) and Barone et al (30) reported that the frequency of Ax LN metastases in pTla disease was 4-7.8\%, and that most of these Ax LNs were not palpable on preoperative examination. Therefore, it is important to be proactive with the tissue diagnosis if it is inconsistent with the progression of primary BC. The differential diagnosis of enlarged LNs includes reactive 

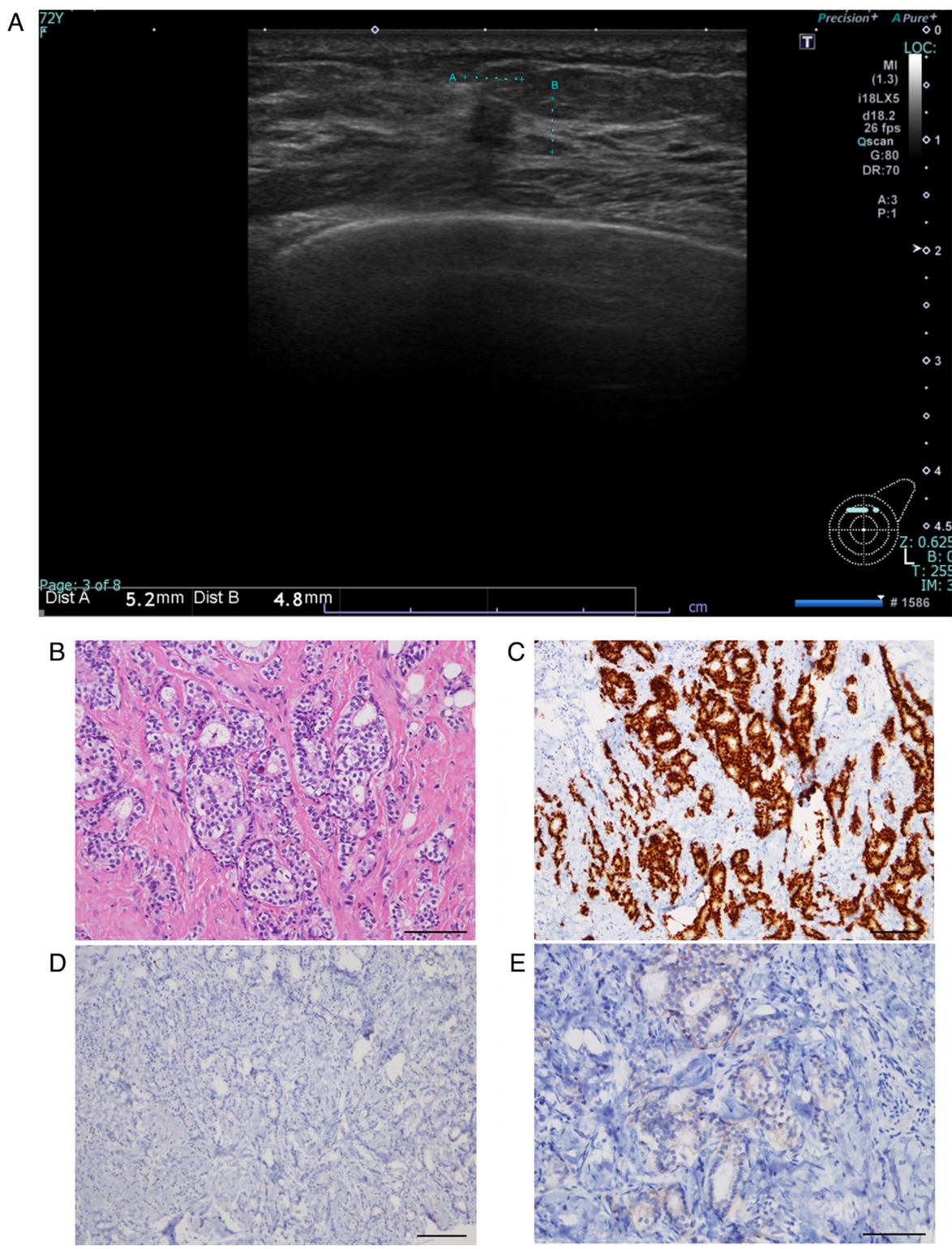

Figure 1. Ultrasound images and histopathological images. (A) On ultrasound examination, a large $(5.2 \times 4.8 \mathrm{~mm})$ irregular internal hypodense mass was found in the nipple areola-complex of the left breast, in the middle and immediately above the nipple. (B) H\&E staining revealed invasive ductal carcinoma of the breast, histological grade I (tubule formation score 2, nuclear atypia score 2, mitotic count score 1). Scale bar, $100 \mu$ m. Immunohistochemical staining for (C) estrogen receptor (90\%), (D) progesterone receptor (0\%) and (E) HER2 (score).

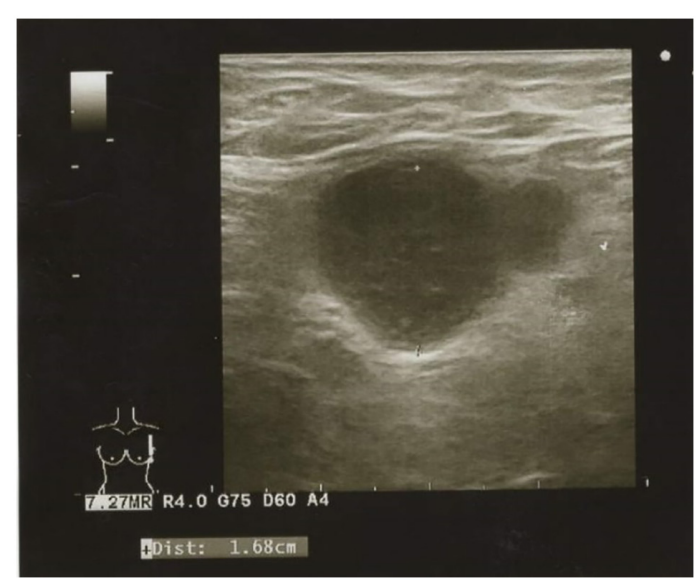

Figure 2. Ultrasound imaging of the axillary lymph nodes. The level I axillary lymph node was enlarged to $16.8 \mathrm{~mm}$ with a loss of medullary structure. Ultrasound-guided core needle biopsy was performed. lymphadenopathy due to rheumatism, inflammatory diseases, as well as ML (31).

Some reports suggest that PET-CT should be performed as a priority in cases with enlarged LNs, regardless the tumour size, as in the present case (32). However, the differential diagnosis between some inflammatory and infectious lesions and malignant lesions is difficult (33). Prior CNB can be used to differentiate between $\mathrm{Ax} \mathrm{LN}$ metastases from $\mathrm{BC}$ and inflammatory disease or ML, avoiding excessive testing and surgically invasive procedures $(20,34)$. In the present case, due to the discrepancy between the small size of the breast tumour and the enlarged Ax LNs, a CNB was performed. As a result, a diagnosis of ML was made.

Third, an immunohistological diagnosis makes it possible to assess the hormone receptor and HER2 status of the LNs. Recently, it was reported that the hormone receptor status may differ between the primary tumour and LN metastases. 

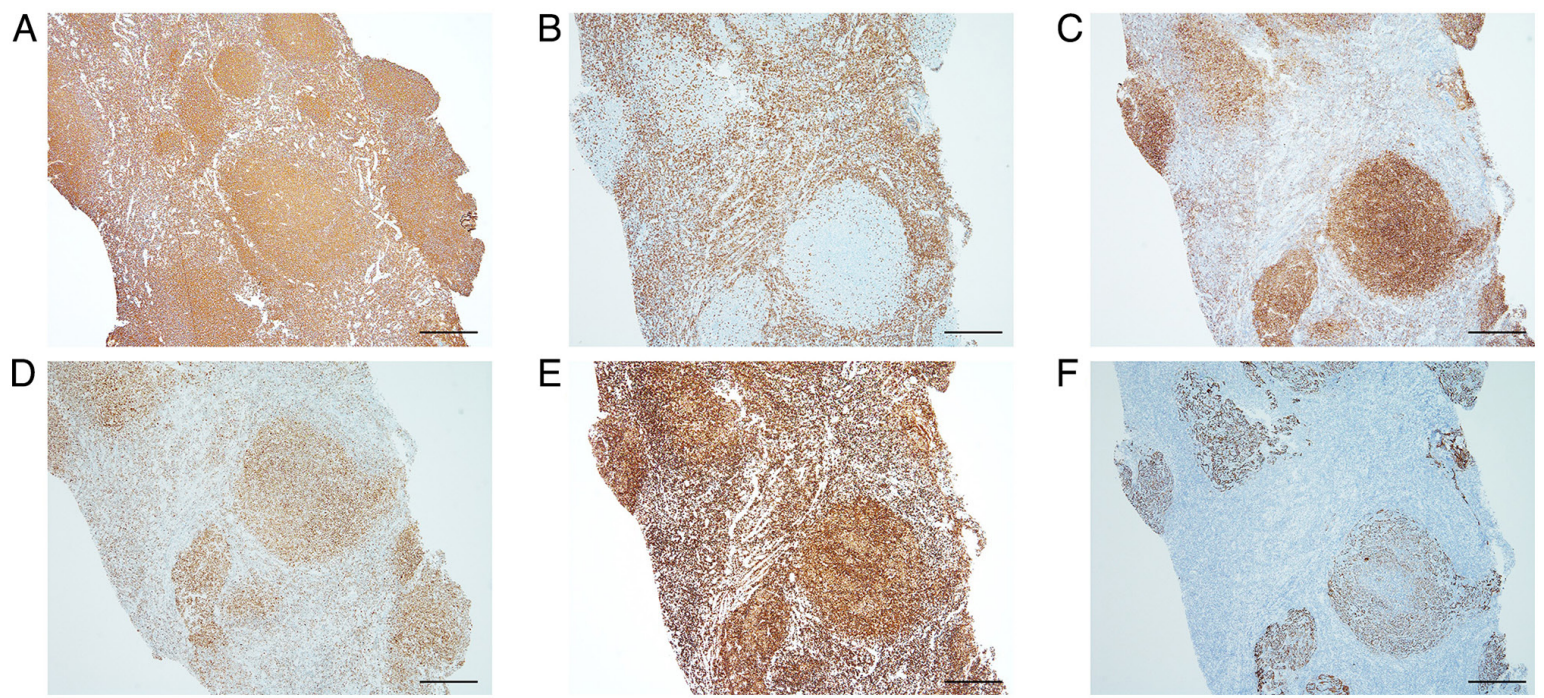

Figure 3. Histopathological examination of the axillary lymph nodes. Immunostaining for (A) CD20; (B) CD3; (C) CD10; (D) Bcl-6; (E) Bcl-2; and (F) CD21. Most of the follicular component cells were positive for CD20, CD10, Bcl-2 and Bcl-6, and negative for CD3. CD21-positive dendritic cells that almost coincided with the follicles were identified, supporting the diagnosis of follicular lymphoma. Scale bar, $200 \mu \mathrm{m}$.
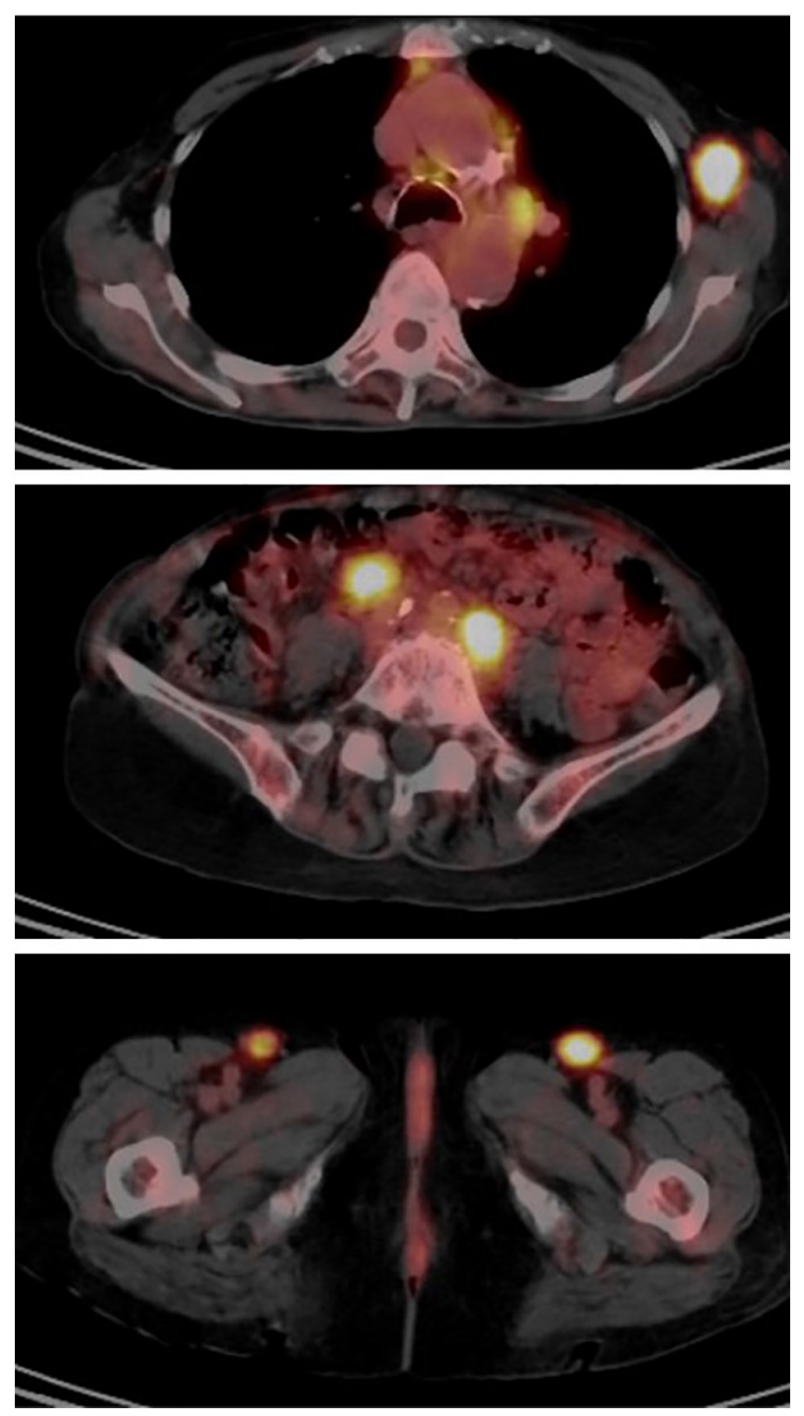

Figure 4. PET-CT examination. High fluorodeoxyglucose accumulation in the mediastinal, bilateral axillary (upper panel), abdominal para-aortic, iliac (middle panel), and bilateral inguinal (lower panel) lymph nodes can be observed.
Nakamura et al (35) reported the therapeutic efficacy of preoperative chemotherapy according to the LN subtype and indicated that metastatic LNs may be an indication for SNB if preoperative chemotherapy results in a pathological complete response.

An immunohistological diagnosis is difficult with FNAC. Woo et al (11) performed FNA for preoperative diagnosis of $\mathrm{ML}$ and found no atypical cells. Consequently, they reported that ML was the definitive postoperative diagnosis by SNLB. Therefore, immunohistological examination is particularly important for the diagnosis of ML.

The European Society for Medical Oncology has long considered surgical resection to be the gold standard biopsy method for staging ML due to the need for adequate tissue samples (36). However, in recent years, an increasing number of reports have shown that the diagnostic accuracy of subtype classification techniques using CNB is comparable to that of surgical resection $(37,38)$, whereas CNB is superior to surgical resection in terms of the waiting period for examination, time required for the examination per se, invasiveness and medical costs $(39,40)$. Both CNB and surgical biopsy of Ax LN specimens may be used to diagnose FL, with comparable results in terms of accuracy.

Finally, the safety and procedures of CNB and FNAC are almost identical. Abnormal LNs are assessed by the thickness of the cortex, the disappearance of hyperechoic areas near the LN hilum, and the uneven distribution of blood flow within the LN $(16,41,42)$. The US-guided approach to the Ax LNs prevents the needle tip from injuring major blood vessels and nerves, thus avoiding complications (43).

Based on the four aforementioned advantages, we recommend aggressive CNB of abnormally large Ax LNs prior to BC surgery. Performing CNB on abnormally large Ax LNs without exception, even in early-stage BCs with a small tumour size, enabled the diagnosis of synchronous $\mathrm{BC}$ and $\mathrm{Ax}$ FL with minimal invasion. Therefore, CNB evaluation of $\mathrm{Ax}$ LNs may continue to play an important role in preoperative $\mathrm{BC}$ screening in the future. 


\section{Acknowledgements}

Not applicable.

\section{Funding}

No funding was received.

\section{Availability of data and materials}

The datasets used and/or analyzed during the current study are available from the corresponding author on reasonable request.

\section{Authors' contributions}

RE wrote the paper. RN and NY revised the manuscript for important intellectual content and technical details. RN and NY can confirm the authenticity of the raw data. TM, SH, IS, $\mathrm{HT}, \mathrm{HH}$ and MO contributed to data acquisition and drafted the manuscript. MI performed the histological examinations and was a major contributor to writing the manuscript. All authors have read and approved the final manuscript.

\section{Ethics approval and consent to participate}

Not applicable.

\section{Patient consent for publication}

Written informed consent was obtained from the patient for publication of this case report and accompanying images.

\section{Competing interests}

The authors declare that they have no competing interests.

\section{References}

1. Roy SD, Stafford JA, Scally J and Selvachandran SN: A rare case of breast carcinoma co-existing with axillary mantle cell lymphoma. World J Surg Oncol 1: 27, 2003.

2. Barranger E, Marpeau O, Uzan S and Antoine M: Axillary sentinel node involvement by breast cancer coexisting with B-cell follicular lymphoma in nonsentinel nodes. Breast J 11: 227-228, 2005.

3. Cox J, Lunt L and Webb L: Synchronous presentation of breast carcinoma and lymphoma in the axillary nodes. Breast 15 246-252, 2006

4. Garg NK, Bagul NB, Rubin G and Shah EF: Primary lymphoma of the breast involving both axillae with bilateral breast carcinoma. World J Surg Oncol 6: 52, 2008.

5. Cuff KE, Dettrick AJ and Chern B: Synchronous breast cancer and lymphoma: A case series and a review of the literature. J Clin Pathol 63: 555-557, 2010.

6. Laudenschlager MD, Tyler KL, Geis MC, Koch MR and Graham DB: A rare case of synchronous invasive ductal carcinoma of the breast and follicular lymphoma. S D Med 63: $123-125,2010$.

7. Sordi E, Cagossi K, Lazzaretti MG, Gusolfino D, Artioli F, Santacroce G, Brandi ML and Piscitelli P: Rare case of male breast cancer and axillary lymphoma in the same patient: An unique case report. Case Rep Med 2011: 940803, 2011.

8. Miles EF and Jacimore LL: Synchronous bilateral breast carcinoma and axillary non-hodgkin lymphoma: A case report and review of the literature. Case Rep Oncol Med 2012: 685919, 2012.
9. Arana S, Vasquez-Del-Aguila J, Espinosa-Bravo M, Peg V and Rubio IT: Lymphatic mapping could not be impaired in the presence of breast carcinoma and coexisting small lymphocytic lymphoma. Am J Case Rep 14: 322-325, 2013.

10. Tamaoki M, Nio Y, Tsuboi K, Nio M, Tamaoki $M$ and Maruyama R: A rare case of non-invasive ductal carcinoma of the breast coexisting with follicular lymphoma: A case report with a review of the literature. Oncol Lett 7: 1001-1006, 2014.

11. Woo EJ, Baugh AD and Ching K: Synchronous presentation of invasive ductal carcinoma and mantle cell lymphoma: A diagnostic challenge in menopausal patients. J Surg Case Rep 22: rjv153, 2016.

12. Brice P, Bastion Y, Lepage E, Brousse N, Haïoun C, Moreau P, Straetmans N, Tilly H, Tabah I and Solal-Céligny P: Comparison in low-tumor-burden follicular lymphomas between an initial no-treatment policy, prednimustine, or interferon alfa: A randomized study from the Groupe d'Etude des Lymphomes Folliculaires. Groupe d'Etude des Lymphomes de l'Adulte. J Clin Oncol 15: 1110-1117, 1997.

13. Solal-Céligny P, Lepage E, Brousse N, Tendler CL, Brice P, Haïoun C, Gabarre J, Pignon B, Tertian G, Bouabdallah R, et al: Doxorubicin-containing regimen with or without interferon alfa-2b for advanced follicular lymphomas: Final analysis of survival and toxicity in the Groupe d'Etude des Lymphomes Folliculaires 86 trial. J Clin Oncol 16: 2332-2338, 1998.

14. Sebban C, Mounier N, Brousse N, Belanger C, Brice P, Haioun C, Tilly H, Feugier P, Bouabdallah R, Doyen C, et al: Standard chemotherapy with interferon compared with CHOP followed by high-dose therapy with autologous stem cell transplantation in untreated patients with advanced follicular lymphoma: The GELF-94 randomized study from the Groupe d'Etude des Lymphomes de l'Adulte (GELA). Blood 108: 2540-2544, 2006.

15. Park S, Koo JS, Kim GM, Sohn J, Kim SI, Cho YU, Park BW, Park VY, Yoon JH, Moon HJ, et al: Feasibility of charcoal tattooing of cytology-proven metastatic axillary lymph node at diagnosis and sentinel lymph node biopsy after neoadjuvant chemotherapy in breast cancer patients. Cancer Res Treat 50: 801-812, 2018.

16. Gentilini $\mathrm{O}$ and Veronesi $\mathrm{U}$ : Abandoning sentinel lymph node biopsy in early breast cancer? A new trial in progress at the European institute of oncology of Milan (SOUND: Sentinel node vs. observation after axillary UltraSouND). Breast 21: 678-681, 2012.

17. Cyr AE, Tucker N, Ademuyiwa F, Margenthaler JA, Aft RL, Eberlein TJ, Appleton CM, Zoberi I, Thomas MA, Gao F and Gillanders WE: Successful completion of the pilot phase of a randomized controlled trial comparing sentinel lymph node biopsy to no further axillary staging in patients with clinical T1-T2 N0 breast cancer and normal axillary ultrasound. J Am Coll Surg 223: 399-407, 2016.

18. Nguyen BM, Halprin C, Olimpiadi Y, Traum P, Yeh JJ and Dauphine C: Core needle biopsy is a safe and accurate initial diagnostic procedure for suspected lymphoma. Am J Surg 208: 1003-1008, 2014.

19. Zinzani PL, Colecchia A, Festi D, Magagnoli M, Larocca A, Ascani S, Bendandi M, Orcioni GF, Gherlinzoni F, Albertini $\mathrm{P}$, et al: Ultrasound-guided core-needle biopsy is effective in the initial diagnosis of lymphoma patients. Haematologica 83: 989-992, 1998.

20. Nakamura R, Yamamoto N, Miyaki T, Itami M, Shina N and Ohtsuka M: Impact of sentinel lymph node biopsy by ultrasound-guided core needle biopsy for patients with suspicious node positive breast cancer. Breast Cancer 25: 86-93, 2018.

21. Bhandari A, Xia E, Wang Y, Sindan N, Kc R, Guan Y, Lin YL, Wang $X$, Zhang $X$ and Wang O: Impact of sentinel lymph node biopsy in newly diagnosed invasive breast cancer patients with suspicious node: A comparative accuracy survey of fine-needle aspiration biopsy versus core-needle biopsy. Am J Transl Res 10: 1860-1873, 2018.

22. Sandrucci S and Mussa A: Sentinel lymph node biopsy and axillary staging of T1-T2 N0 breast cancer: A multicenter study. Semin Surg Oncol 15: 278-283, 1998.

23. Gulec SA, Moffat FL, Carroll RG and Krag DN: Gamma probe guided sentinel node biopsy in breast cancer. Q J Nucl Med 41: 251-261, 1997.

24. Sener SF, Winchester DJ, Brinkmann E, Winchester DP, Alwawi E, Nickolov A, Perlman RM, Bilimoria M, Barrera E and Bentrem DJ: Failure of sentinel lymph node mapping in patients with breast cancer. J Am Coll Surg 198: 732-736, 2004.

25. Kramer EL: Lymphoscintigraphy: Radiopharmaceutical selection and methods. Int J Rad Appl Instrum B 17: 57-63, 1990. 
26. Albertini JJ, Lyman GH, Cox C, Yeatman T, Balducci L, Ku N Shivers S, Berman C, Wells K, Rapaport D, et al: Lymphatic mapping and sentinel node biopsy in the patient with breast cancer. JAMA 276: 1818-1822, 1996.

27. Veronesi U, Paganelli G, Galimberti V, Viale G, Zurrida S, Bedoni M, Costa A, de Cicco C, Geraghty JG, Luini A, et al: Sentinel-node biopsy to avoid axillary dissection in breast cancer with clinically negative lymph-nodes. Lancet 349: 1864-1867, 1997.

28. Clarke M, Collins R, Darby S, Davies C, Elphinstone P, Evans V, Godwin J, Gray R, Hicks C, James S, et al: Early breast cancer Trialists' Collaborative group (EBCTCG): Effects of radiotherapy and of differences in the extent of surgery for early breast cancer on local recurrence and 15-year survival: An overview of the randomised trials. Lancet 366: 2087-2106, 2005.

29. Fortunato L, Santoni M, Drago S, Gucciardo G, Farina M, Cesarini C, Cabassi A, Tirelli C, Terribile D, Grassi GB, et al: Sentinel lymph node biopsy in women with pT1a or 'microinvasive' breast cancer. Breast 17: 395-400, 2008.

30. Barone JE, Tucker JB, Perez JM, Odom SR and Ghevariya V: Evidence-based medicine applied to sentinel lymph node biopsy in patients with breast cancer: Am Surg 71: 66-70, 2005.

31. Kim KH, Son EJ, Kim EK, Ko KH, Kang H and Oh KK: Safety and efficiency of the ultrasound-guided large needle core biopsy of axilla lymph nodes. Yonsei Med J 49: 249-254, 2008

32. Brennan ME and Houssami N: Evaluation of the evidence on staging imaging for detection of asymptomatic distant metastases in newly diagnosed breast cancer. Breast 21: 112-123, 2012.

33. Kawada N, Uehara H, Hosoki T, Takami M, Shiroeda H, Arisawa T and Tomita Y: Usefulness of dual-phase 18F-FDG $\mathrm{PET} / \mathrm{CT}$ for diagnosing small pancreatic tumors. Pancreas 44: 655-659, 2015

34. Pugliese N, Perna MD, Cozzolino I, Ciancia G, Pettinato G, Zeppa P, Varone V, Masone S, Cerchione C, Pepa RD, et al: Randomized comparison of power doppler ultrasonography-guided core-needle biopsy with open surgical biopsy for the characterization of lymphadenopathies in patients with suspected lymphoma. Ann Hematol 96: 627-637, 2017.

35. Nakamura R, Hayama S, Sonoda I, Miyaki T, Itami M and Yamamoto N: Clinical impact of the biology of synchronous axillary lymph node metastases in primary breast cancer on preoperative treatment strategy. J Surg Oncol 123. 1513-1520, 2021.
36. Tilly H, Vitolo U, Walewski J, da Silva MG, Shpilberg O, André M, Pfreundschuh $\mathrm{M}$ and Dreyling M; ESMO guidelines working group: Diffuse large B-cell lymphoma (DLBCL): ESMO clinical practice guidelines for diagnosis, treatment and follow-up. Ann Oncol 23 (Suppl 7): vii78-vii82, 2012.

37. Chatani S, Hasegawa T, Kato S, Murata S, Sato Y, Yamaura H, Yamamoto K, Yatabe Y and Inaba Y: Image-guided core needle biopsy in the diagnosis of malignant lymphoma: Comparison with surgical excision biopsy. Eur J Radiol 127: 108990, 2020.

38. Hu Q, Naushad H, Xie Q, Al-Howaidi I, Wang M and Fu K: Needle-core biopsy in the pathologic diagnosis of malignant lymphoma showing high reproducibility among pathologists. Am J Clin Pathol 140: 238-247, 2013.

39. Lachar WA, Shahab I and Saad AJ: Accuracy and cost-effectiveness of core needle biopsy in the evaluation of suspected lymphoma: A study of 101 cases. Arch Pathol Lab Med 131: 1033-1039, 2007.

40. Ardeshna KM, Qian W, Smith P, Braganca N, Lowry L, Patrick P, Warden J, Stevens L, Pocock CF, Miall F, et al: Rituximab versus a watch-and-wait approach in patients with advanced-stage, asymptomatic, non-bulky follicular lymphoma: An open-label randomised phase 3 trial. Lancet Oncol 15: 424-435, 2014.

41. Feu J, Tresserra F, Fábregas R, Navarro B, Grases PJ, Suris JC, Fernández-Cíd A and Alegret X: Metastatic breast carcinoma in axillary lymph nodes: In vitro US detection. Radiology 205: 831-835, 1997.

42. Vassallo P, Wernecke K, Roos N and Peters PE: Differentiation of benign from malignant superficial lymphadenopathy: The role of high-resolution US. Radiology 183: 215-220, 1992.

43. Abe H, Schmidt RA, Sennett CA, Shimauchi A and Newstead GM: US-guided core needle biopsy of axillary lymph nodes in patients with breast cancer: Why and how to do it. Radiographics 27 (Suppl 1): S91-S99, 2007.

This work is licensed under a Creative Commons Attribution-NonCommercial-NoDerivatives 4.0 International (CC BY-NC-ND 4.0) License. 